University of South Carolina

Scholar Commons

Theses and Dissertations

2018

\title{
Assessing the Barriers to Cardiac Care in Carriers of Duchenne and Becker Muscular Dystrophy
}

Lauren Renae Eekhoff

University of South Carolina

Follow this and additional works at: https://scholarcommons.sc.edu/etd

Part of the Medical Genetics Commons

Recommended Citation

Eekhoff, L.(2018). Assessing the Barriers to Cardiac Care in Carriers of Duchenne and Becker Muscular Dystrophy. (Doctoral dissertation). Retrieved from https://scholarcommons.sc.edu/etd/4463

This Open Access Dissertation is brought to you by Scholar Commons. It has been accepted for inclusion in Theses and Dissertations by an authorized administrator of Scholar Commons. For more information, please contact digres@mailbox.sc.edu. 
Assessing the Barriers to Cardiac Care in Carriers of Duchenne and Becker Muscular Dystrophy

by

Lauren Renae Eekhoff

Bachelor of Science

Dordt College, 2016

Submitted in Partial Fulfillment of the Requirements

For the Degree of Master of Science in

\author{
Genetic Counseling \\ School of Medicine \\ University of South Carolina
}

2018

Accepted by:

Janice Edwards Director of Thesis

Ann Martin, Reader

EJ Prijoles, Reader

Cheryl L. Addy, Vice Provost and Dean of the Graduate School 
(C) Copyright by Lauren Eekhoff, 2018

All Rights Reserved. 


\section{ACKNOWLEDGEMENTS}

Thank you to everyone who made this project and my time in graduate school possible. To my professors, supervisors, friends, and parents-you have all influenced me and made me into the genetic counselor I am today. I cannot thank you enough for your support. 


\begin{abstract}
Duchenne and Becker muscular dystrophy (DBMD) are X-linked conditions due to mutations within the dystrophin gene that cause progressive muscle weakness, respiratory insufficiency, and cardiomyopathy in affected males. Approximately twothirds of women who have a son with DBMD are carriers of the condition. Carriers typically do not manifest muscular symptoms but are at risk for cardiac abnormalities such as dilated cardiomyopathies. The American Academy of Pediatrics (AAP) recommends that carriers of DBMD receive a complete cardiac evaluation by a cardiologist that includes an echocardiogram and electrocardiogram (EKG) with reevaluation every five years. According to a recent study ${ }^{33}$, as many as $35.6 \%$ of carriers are not adhering to the AAP recommendations despite having knowledge of their carrier status. Limited research has been conducted into the barriers that carriers face in accessing recommended cardiac screening. We surveyed 60 carriers of DBMD and conducted semi-structured telephone interviews with 11 carriers who in the last five years either had not seen a cardiologist, had an echocardiogram, or had an EKG to determine the perceived challenges that carriers face in obtaining appropriate cardiac care. From the interviews, seven major themes emerged: 1) a lack of awareness among healthcare providers about cardiac risks 2) a responsibility among carriers for self-education and self-advocacy 3) frustration with misinformation received 4) a lack of concern due to lack of family history and/or a perceived healthy lifestyle 5) a lack of information-sharing with other carriers in the family 6) a priority of the healthcare needs of family members
\end{abstract}


over personal healthcare needs and 7) a belief that conversations about carrier status should begin at a younger age. Increased awareness, health education regarding risks for carriers, and advocacy efforts are needed for healthcare providers and carriers in order to ensure that this entire population receives the cardiac care they need. 


\section{TABLE OF CONTENTS}

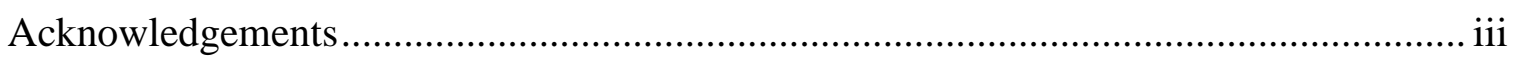

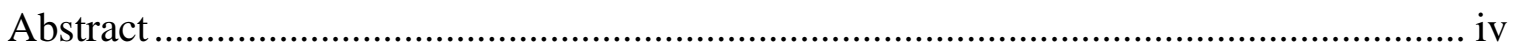

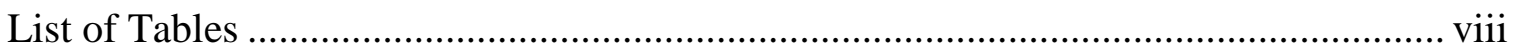

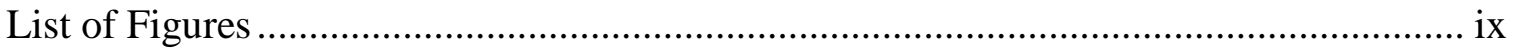

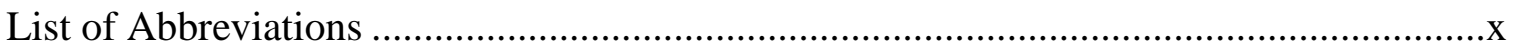

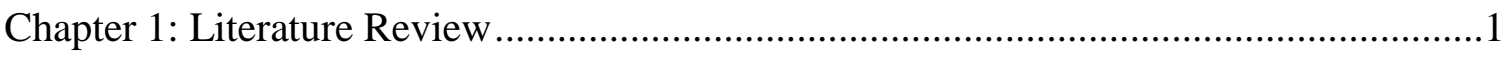

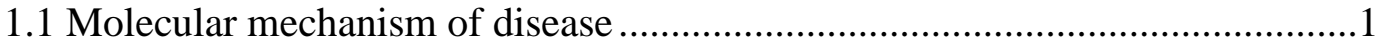

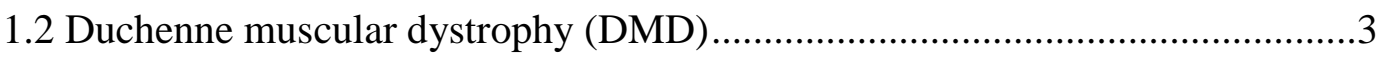

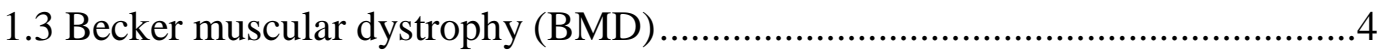

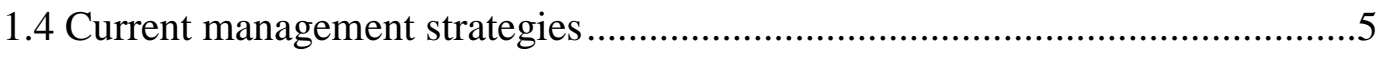

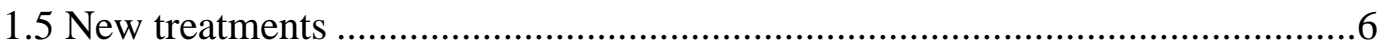

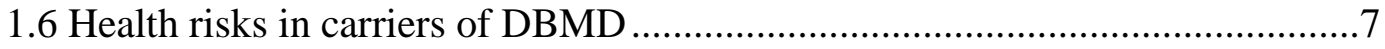

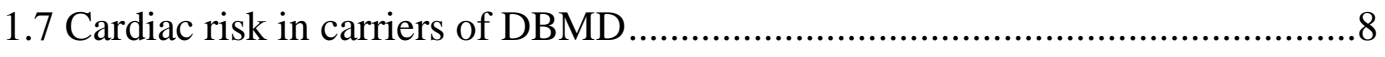

1.8 Surveillance recommendations for DBMD carriers ...................................10

1.9 Adherence to surveillance recommendations among carriers .......................11

Chapter 2: Assessing the Barriers to Cardiac Care in Carriers of

Duchenne and Becker Muscular Dystrophy ..................................................15

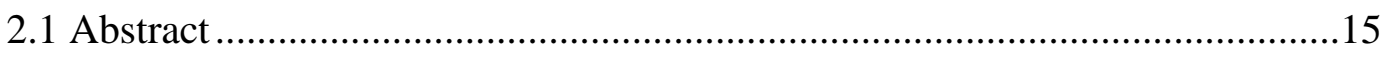

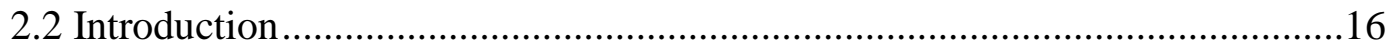

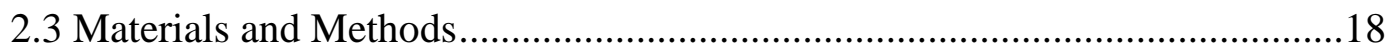




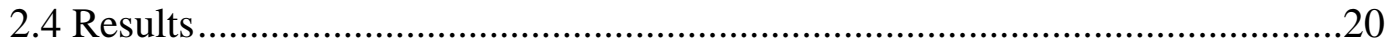

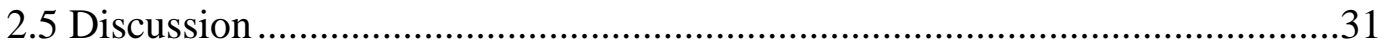

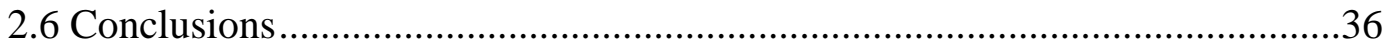

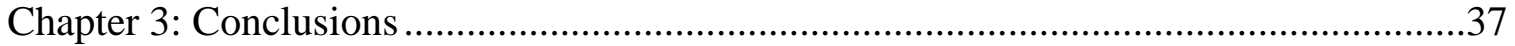

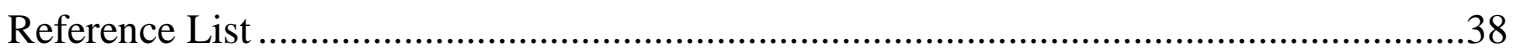

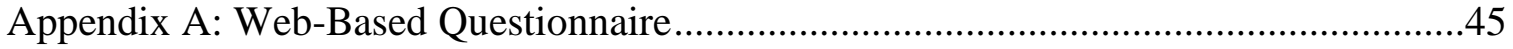

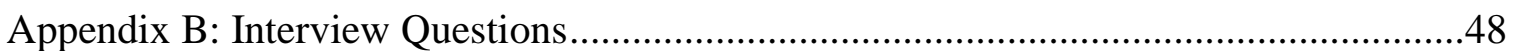

Appendix C: Major Themes and Representative Quotes.............................................50 


\section{LIST OF TABLES}

Table 2.1 Background information of carriers interviewed ..........................................24 


\section{LIST OF FIGURES}

Figure 1.1 The dystroglycan complex ........................................................................

Figure 2.1 States represented by carriers interviewed. ...........................................21

Figure 2.2 Adherence to cardiac screenings among carriers interviewed based upon AAP

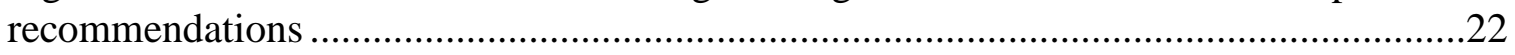

Figure 2.3 Amount of time between participants' discovery of carrier status and age at present 


\section{LIST OF ABBREVIATIONS}

AAV $\ldots \ldots$ American Academy of Pediatrics




\section{CHAPTER 1: \\ LITERATURE REVIEW}

\subsection{Molecular mechanism of disease}

Duchenne and Becker muscular dystrophy (DBMD) are neuromuscular disorders known as dystrophinopathies, caused by mutations within the dystrophin gene located on the $\mathrm{X}$ chromosome at $\mathrm{Xp} 21.1$ and inherited in an $\mathrm{X}$-linked recessive fashion. ${ }^{1}$ Dystrophin is one of the largest known genes at $2.2 \mathrm{Mb}$ and is comprised of 79 exons. The dystrophin gene contains three promoters: $\mathrm{M}, \mathrm{B}$, and $\mathrm{P}$. The $\mathrm{M}$ promoter encodes for a rod-shaped dystrophin protein which is found primarily in skeletal and cardiac muscle. Small amounts of dystrophin are also found in nerve cells in the brain; however, the exact function of the protein in the brain is not entirely known. The B promoter is responsible for production of dystrophin in the brain while the $\mathrm{P}$ promoter produces dystrophin expressed specifically in Purkinje cells in the brain. ${ }^{2}$

Dystrophin found in skeletal and cardiac muscle functions in the dystroglycan complex (DGC) to connect intracellular actin filaments at the $\mathrm{N}$-terminus to glycoproteins of the sarcolemma at the C-terminus. The DGC is a complex made up of integral membrane proteins as well as peripheral proteins that works to provide support for cardiac or skeletal muscle cells during contraction by connecting actin filaments to the extracellular matrix (ECM). Dystrophin functions to stabilize the plasma membrane by carrying signals from sarcolemma contractions to the ECM. ${ }^{2}$ A figure representation of the DGC and its associated proteins is shown in Figure 1.1. 


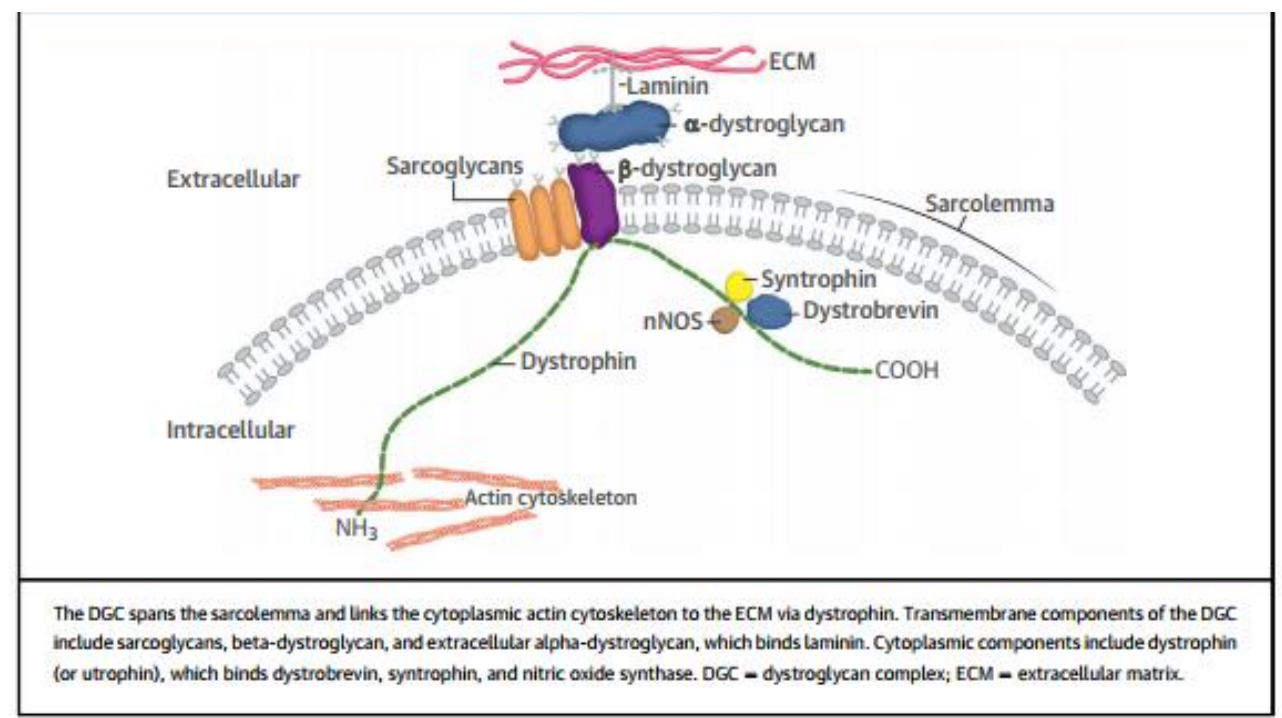

Figure 1.1 The dystroglycan complex ${ }^{2}$

Due to its large size, the dystrophin gene is highly susceptible to mutations.

Different types of muscular dystrophies arise from mutations within the dystrophin protein or within any of the other DGC-associated proteins. Exonic deletions comprise $65 \%$ of all dystrophin mutations. Meanwhile, exonic duplications represent up to $10 \%$ of all dystrophin mutations. Both exonic duplications and deletions are traditionally detected previously by PCR analysis and more recently, by MLPA and aCGH analysis. ${ }^{3}$ Exonic duplications and deletions tend to be present at "hot spots" within the gene located in exons 45-53 which ultimately result in a frameshift. Small mutations such as nonsense and missense mutations, microdeletions, splice site mutations, and insertions make up the remaining 25-30\%. These small mutations are undetectable by PCR but can be detected using techniques such as Sanger sequencing and next generation sequencing (NGS). Point mutations are not bound by hot spots and have been observed to be randomly distributed across the whole dystrophin gene. However, missense mutations have been found mostly at the $\mathrm{N}$ and $\mathrm{C}$-termini. ${ }^{4}$ A lack of functional dystrophin due to a mutation compromises the membranes of the skeletal and cardiac muscle cells, and the cells are at 
an increased risk for stress-induced damage from contraction. A damaged plasma

membrane leads to an increase in calcium entering into the cell which results in cell death and the resulting phenotypic muscle weakness and wasting. ${ }^{2}$

\subsection{Duchenne muscular dystrophy (DMD)}

Affecting between 1 in 3802 to 1 in 6291 boys in the United States, DMD is a progressive muscle-wasting disorder. ${ }^{5}$ DMD is the most severe of the childhood muscular dystrophies. ${ }^{1}$ Over 1000 mutations have been identified in the dystrophin gene that are responsible for causing DMD with a penetrance of $100 \% .{ }^{6}$ Pathogenic mutations in DMD cause a lack of dystrophin protein production which in turn cause severe, early-onset symptoms in DMD. ${ }^{7}$

Clinically, absent dystrophin protein can present initially as motor delays and hypotonia. ${ }^{8}$ Calf pseudohypertrophy, Gower maneuver, and toe walking or an abnormal gait will present between the ages of two and five. ${ }^{9}$ As the disorder progresses, the risk increases to develop additional symptoms such as attention deficit hyperactivity disorder, autism, and obsessive-compulsive disorder suggesting a potential effect on neurocognitive function. Not much is known about the role of dystrophin in neurocognitive disorders; however, dystrophin is suspected to work closely with Purkinje fibers in the brain. In fact, approximately one-third of those diagnosed with DMD will experience a cerebellar function-related disorder like dyslexia, mild intellectual disability, or impairment in verbal working memory or in performing motor tasks. ${ }^{10}$ Additionally, because this is a progressive disorder, most boys with DMD will be wheelchair-bound by the age of twelve. Scoliosis and respiratory insufficiency are common with increasing age. 
Cardiac involvement is present in almost all individuals with DMD. These cardiac abnormalities can include dilated cardiomyopathy and arrhythmia. Heart muscle wasting is the cause of dilated cardiomyopathy which usually begins in the left ventricle and occurs when the cardiac muscle thins and is unable to pump adequate amounts of blood to the body. Myocardial fibrosis is also associated with dysfunction with the left ventricle and is one of the most common histological signs of heart failure. ${ }^{11,12}$ Cardiac involvement often presents at approximately ten years of age and will affect almost all boys after age 18. Pre-clinical detection is possible through electrocardiograph and echocardiograph findings. Due to low physical activity with increasing age, most boys are relatively asymptomatic in regard to cardiac manifestation. ${ }^{13}$ However, if no steroid therapy is administered, death typically occurs in the early twenties due to congestive heart failure and can be predicted by the level of progressing respiratory insufficiency. ${ }^{14}$

\subsection{Becker muscular dystrophy (BMD)}

Becker muscular dystrophy is less frequent in the U.S. population than DMD and generally has milder symptoms. Compared to DMD, the mutations that result in BMD keep the transcript within the reading frame causing a protein that is abnormal or present in reduced amount instead of completely absent. ${ }^{7}$ Boys with BMD will typically present later in childhood around age twelve with limb girdle weakness and calf hypertrophy. However, BMD is a variable disorder. Some individuals present with muscle weakness later in life into mid to late adulthood, and some reported variants only cause weakness in the quadriceps or weakness as the result of exercise. Cognition is generally not impaired in cases of BMD. Individuals with BMD will generally remain ambulant much longer than those with DMD but are also at an increased risk for cardiomyopathy. ${ }^{14}$ 
Additionally, death does not usually occur until the fourth or the fifth decade of life.

Cardiomyopathy is often the cause of death in both DMD and BMD. ${ }^{7}$

\subsection{Current management strategies}

There is currently no cure for muscular dystrophy. Those with muscular dystrophy require a multidisciplinary team to manage their symptoms including yearly visits to neurologists, cardiologists, pulmonologists, physical and occupational therapists, and nutritionists. ${ }^{14}$ Glucocorticosteroids are often the course of treatment used to maintain muscle strength and slow muscle wasting in addition to maintaining lung function, prolonging ambulation, and reducing the incidence of scoliosis. ${ }^{15}$ The two most common corticosteroids implemented are prednisone and deflazacort, also known as Emflaza. Mechanisms by which these corticosteroids ameliorate muscular dystrophy symptoms are not completely understood. However, it is known that prednisone acts in an anti-inflammatory way to increase skeletal muscle force. Deflazacort functions to regenerate and differentiate muscle cells. ${ }^{16}$ As of 2017, deflazacort was FDA-approved in patients over the age of 5 with DMD, making it the second drug to be approved for treatment

Orthopedic surgery is often recommended in managing DMD or BMD. Special consideration must be given to those individuals who undergo surgery as they are at an increased risk for complications related to lung and cardiac function. In order to maintain cardiac function, lung function must be maintained as well. Appropriately functioning lungs reduce respiratory complications as well as reduced stress on the heart. ${ }^{1}$ 


\subsection{New treatments}

Several therapeutic modalities are being investigated as potential treatments for patients with muscular dystrophy. Exon-skipping is one potential therapy for muscular dystrophy patients. Data suggests that up to $80 \%$ of DMD could be amenable to exonskipping therapies. Currently in clinical trials, these drugs allow for skipping of mutated exons in the pre-mRNA to produce a more truncated form of dystrophin and minimize the effects of the mutation. ${ }^{16}$ The only FDA-approved exon-skipping drug, eteplirsen, functions in skipping of exon 51, in which $13 \%$ of DMD cases will have a mutation. Drugs designed for skipping of exons 44, 52, 50, 43, 55, 8 and 35 are currently in preclinical trials.

Gene therapy, another potential treatment, uses a virus to deliver a functioning dystrophin gene to cardiac and skeletal muscle cells in order to produce functioning dystrophin protein. Because of its large size, the dystrophin gene is unable to fit inside a traditionally used adeno-associated virus (AAV). Thus, a truncated dystrophin gene is created so as to produce a Becker-like phenotype in the receiving individual. However, the current challenge includes an adverse immune response from the host. ${ }^{16}$ Several gene therapy trials are ongoing for DMD. Notably, in January of 2018, Dr. Mendell and his team at Nationwide Children's Hospital, delivered the first dose using a systemic microdystrophin gene therapy. Gene therapy promises to be a potential avenue for muscular dystrophy treatment.

Gene editing has also recently surfaced. One specific genome editing tool, CRISPR/Cas9, provides much potential for curative muscular dystrophy treatment. CRISPR/Cas 9 makes use of a guide RNA to target a specific location in the genome and 
allows for insertion of a functioning dystrophin gene due to naturally-occurring DNA repair mechanisms. Due to potential off-target effects as well as ethical dilemmas surrounding the editing of the human genome, CRIPR/Cas9 is still in the pre-clinical phase of development. $^{16}$

Currently in clinical trials, stem cell therapy offers the potential for stem cells which are able to differentiate into any cell type, to regenerate damaged muscle cells in muscular dystrophy patients. ${ }^{16}$

\subsection{Health risks in carriers of DBMD}

Because muscular dystrophy is caused by a mutation on the $\mathrm{X}$ chromosome, males are generally affected while females are carriers. According to Davie and Emery, ${ }^{17}$ one third of muscular dystrophy cases are caused by a de novo mutation, and the remaining two-thirds of cases are inherited from a mother who is a carrier. One study ${ }^{18}$ of mothers of sons with muscular dystrophy found the carrier frequency for DMD to be 58\% and the carrier frequency of BMD to be about $90 \%$. Importantly, carriers of DMD and BMD are at increased risk for specific health concerns.

Penetrance of symptoms is variable in female carriers, and the spectrum of symptoms is wide. Carriers of DMD are generally more severely affected than carriers of BMD. ${ }^{19}$ One study ${ }^{20}$ determined that up to $7.8 \%$ of female carriers are symptomatic with muscle wasting, myalgia, or muscle cramps. These symptoms had a variable onset between the ages of 2 and 47 years old. While some carriers exhibited a severe DMD-like phenotype, others had adult-onset, less severe symptoms.

A study done in the Netherlands by Hoogerwaard et al. ${ }^{7}$ similarly found that $19 \%$ of DMD female carriers and 16\% of BMD female carriers exhibited muscle weakness. 
When cardiac abnormalities were taken into consideration, $22 \%$ of carriers exhibited some symptoms of muscular dystrophy.

A possible explanation for selective female carriers experiencing symptoms could be due to skewed $\mathrm{X}$-inactivation (XCI). XCI is the process by which females undergo dosage equalization of the $\mathrm{X}$ chromosome. Most females in the general population have a random pattern of inactivation and thus are mosaic for maternal and paternal $\mathrm{X}$ chromosomes. A non-random XCI pattern could be one explanation for a manifesting carrier and may even explain age of onset of symptoms as well as severity. However, there is still a lack of absolute correlation between a muscular dystrophy phenotype in female carriers and non-random XCI. In fact, Soltanzadeh et al. ${ }^{19}$ found in their study of 13 manifesting carriers that only five carriers exhibited nonrandom X-inactivation (38\%) which is consistent with other reports suggesting that skewed XCI cannot be the only explanation for symptoms in manifesting carriers. More research is needed in this area to determine the impact of $\mathrm{X}$-inactivation on manifesting female carriers. ${ }^{21,22}$ Genetic modifiers may be another factor influencing the manifestation of symptoms in carriers. Genetic modifiers in DMD have been shown to affect age of onset of symptoms, affected muscle groups, disease progression, and disease severity. ${ }^{23}$

\subsection{Cardiac risk in carriers of DBMD}

Most female carriers do not show any outward symptoms of muscular dystrophy. However, carriers may exhibit a wide range of cardiac abnormalities ranging from mild findings on echocardiogram to hypertrophic abnormalities, left ventricular dilation (which can be considered the precursor to dilated cardiomyopathy), and dilated cardiomyopathies. ${ }^{24,25}$ These cardiac issues pose serious health threats to carriers and in 
some cases require a transplant or can even result in death. ${ }^{26}$ Approximately $60 \%$ of DMD and BMD carriers have cardiac abnormalities ${ }^{25}$ with one study ${ }^{27}$ finding dilated cardiomyopathies in approximately $10.9 \%$ of carriers. Dilated cardiomyopathies have the potential to develop heart failure - requiring heart transplantation. Another study ${ }^{7}$ of 129 Dutch carriers found that $8 \%$ of carriers of DMD displayed dilated cardiomyopathy with an additional $18 \%$ of both DMD and BMD carriers presenting with dilation of the left ventricle on echocardiogram and no presenting muscle weakness. Soltanzadeh and colleagues ${ }^{19}$ determined in a study of 13 manifesting carriers that $38 \%$ exhibited decreased systolic function on echocardiogram. In a study ${ }^{24}$ of 36 carriers utilizing cardiac magnetic resonance imaging (MRI), myocardial damage and fibrosis were present in $44 \%$ of carriers. Yet another study ${ }^{27}$ of 197 female carriers found that preclinical or clinically-detected myocardial anomalies were found in $84.3 \%$ of cases of DMD and BMD carriers. Furthermore, the significance of cardiac involvement increased with age with $54.5 \%$ of carriers aged 5 to 16 years old experiencing cardiac involvement and $90.2 \%$ in those older than 16 years. Significant cardiac disease is not common in those under 16 years of age. Cardiomyopathies tend to develop in the fourth or fifth decade of life and progress slowly. ${ }^{21}$

One study conducted by McCaffrey et al. ${ }^{28}$ found that carriers showed abnormalities on cardiac MRI 3-33\% of the time depending upon the definition of cardiomyopathy and different measurements such as left ventricular fractional shortening and left ventricular ejection fraction. Based on echocardiogram, they found that $7-13 \%$ exhibited significant systolic dysfunction. They additionally found that cardiomyopathy in all cases was not associated with mutation type, DMD vs. BMD phenotype, creatine 
kinase level, the presence of muscle symptoms, or even age. All of the subjects in this study were asymptomatic — reporting no intolerance to exercise, breathlessness, arrhythmias, or cardiac failure.

\subsection{Surveillance recommendations for DBMD carriers}

According to the American Academy of Pediatrics Section on Cardiology and Cardiac Surgery published in $2005,{ }^{1}$ carriers should be made aware of their risk for cardiomyopathy and educated on the signs of heart failure. Additionally, they should be referred to a cardiac specialist for a complete cardiac evaluation in late adolescence or early adulthood—including a history and physical examination, electrocardiogram (EKG), and a transthoracic echocardiogram. Re-evaluation with a cardiologist should occur every five years beginning between the ages of 25 and 30 . Treatment of cardiomyopathy in carriers is similar to treatment for individuals with DBMD as outlined in the American Academy of Pediatrics (AAP) guidelines.

While echocardiogram is the current screening standard for cardiomyopathy, cardiac MRI is increasingly becoming the preferred method of screening used by cardiologists. Cardiac MRI, also known as cardiovascular magnetic resonance (CMR) is a tool used to detect myocardial fibrosis, a sign of cardiomyopathy. The use of cardiac MRI could detect subtle pathologies of the myocardium in the event of a normal echocardiograph evaluation. Cardiac MRI is increasingly becoming a preferred screening tool to identify patients at increased risk of cardiac abnormalities and to identify those patients that should begin treatment so as to delay the progression of the cardiomyopathy. A study conducted by Mavrogeni et al. ${ }^{29}$ determined that up to $66 \%$ of carriers will present with an abnormal finding detected by CMR whereas only $17 \%$ of those carriers 
would present with an abnormal echocardiogram. ${ }^{24}$ A recent study ${ }^{30}$ performed on a small group of 15 carriers found that all DMD carriers exhibited cardiac abnormalities when screened with cardiac MRI.

Treatment for cardiomyopathy in carriers is similar to the treatment of cardiomyopathy in patients with DBMD. ${ }^{1}$ Guidelines for management of patients with cardiomyopathies recommend implementation of drugs such as angiotensin converting enzyme inhibitors or beta-blockers. ${ }^{31}$ ACE inhibitors prevent the conversion of angiotensin I to angiotensin II which ultimately lowers artery resistance, increases venous capacity, increases cardiac output and index, increases stroke volume, and increases natriuresis. Beta-blockers bind to beta-adrenoceptors in order to block norepinephrine and epinephrine from binding. This reduces stimulation of heart rate, contractility, electrical conduction, and relaxation rate. ${ }^{32}$

\subsection{Adherence to surveillance recommendations among carriers}

According to recent research, female carriers of DMD or BMD may not be adhering to the recommendations outlined by the AAP. One study ${ }^{33}$ found that of 833 carriers, $35.6 \%$ of them had never had a cardiac evaluation despite knowing their carrier status. A similar study ${ }^{26}$ of 137 known carriers and 45 of unknown status found that only 45.5\% of confirmed female carriers had had an echocardiogram in the last five years with $21 \%$ of them never having had an echocardiogram. While known carriers were twice as likely to have had an echocardiogram in the last five years than those of unknown status, having a son recently diagnosed with muscular dystrophy had no significant effect on whether or not an echocardiogram was performed recently. 
Many factors could contribute to a lack of adherence to the AAP recommendations in carriers. According to Bobo et al. ${ }^{33} 69 \%$ of female carriers stated that their healthcare providers were aware that they were a carrier of DBMD. Those carriers that had an informed healthcare provider were significantly more likely to have had a cardiac evaluation when compared with those women whose healthcare providers were not aware of their carrier status. This study found that certain factors increased a carrier's likelihood of having a heart test including being over the age of 49 , having a female relative with heart disease, having awareness of their cardiomyopathy risk, and having an informed healthcare provider.

Bobo and colleagues ${ }^{33}$ also found that cost was a factor that inhibited women from participating in cardiac surveillance. In addition, having no symptoms of heart disease, receiving no recommendations from a healthcare provider, having no awareness of cardiac risks, and having no muscle weakness were all reasons for not pursuing cardiac screening. This study found that $37.1 \%$ of carriers had never heard or read about their increased risk for cardiomyopathy in the past which suggests that a lack of knowledge of associated cardiac risk is a potential barrier.

Many carriers of DBMD who are aware of their carrier status do not seem to be following self-care recommendations regarding cardiac surveillance as detailed by the AAP even though up to one in ten may experience overt cardiac failure. ${ }^{34}$ Various factors may contribute to challenges experienced by this population in obtaining appropriate cardiac surveillance including:

1) Carriers may have received inadequate and insufficient education at the time that they were informed of their carrier status. 
2) If the individual's carrier status was revealed at the same time period in which her son was diagnosed with muscular dystrophy, her own diagnosis could have been overshadowed by the information of her son's diagnosis.

3) Carriers may refrain from cardiac surveillance because of a perceived low risk of developing a cardiomyopathy. This may be because she is unaware of the severity of cardiomyopathies, because she has other female carrier relatives who have not developed symptoms or are also not adhering to the recommendations, or again, because of a lack of education.

4) Some carriers may have limited access to healthcare. Socioeconomic status, accessibility to a vehicle, time it takes to get to the appointment, availability of the cardiologist, and other healthcare disparities potentially factor into healthcare access.

5) Caring for a son with muscular dystrophy has taken precedence over the carrier's own health. Studies have shown that those who take the role of a caregiver experience stress, distress, high caregiving demands, and are more likely to have psychological effects related to the caregiving. ${ }^{35}$

\section{Hypothesis}

Various barriers may inhibit female carriers of DBMD from obtaining appropriate cardiac surveillance. Lack of education, perceived low cardiomyopathy risk, lack of accessibility to a cardiologist, burden of being a caregiver for an affected son or sons, or a combination of factors may contribute to poor adherence to the AAP recommendations in female carriers. In order to identify the specific barriers that female carriers experience, this study will explore three specific aims: 
1) Assess the experience of female carriers at their initial discovery of their carrier status.

2) Determine the specific cardiac care practices that female carriers are following or not following.

3) Identify perceived challenges and barriers to appropriate cardiac care.

By making an effort to understand the needs of this patient population, healthcare professionals may be able to better address specific concerns that this population is facing in obtaining appropriate cardiac self-care. This presents as an opportunity for genetic counselors to become more aware of the needs of this population themselves but also to raise awareness and to advocate for this population that may be underserved. Through one-on-one interviews, this study aims to evaluate the barriers to self-care that carriers of DMD or BMD are experiencing. This is primarily an exploratory study, and its goal is to provide insight into a population to highlight unique areas of concern or unmet needs that could be addressed by genetic counselors and other healthcare providers. 


\section{CHAPTER 2:}

\section{ASSESSING THE BARRIERS TO CARDIAC CARE IN CARRIERS OF DUCHENNE AND BECKER MUSCULAR DYSTROPHY ${ }^{1}$}

\subsection{Abstract}

Purpose: Duchenne and Becker muscular dystrophy (DBMD) are X-linked conditions causing progressive muscle weakness, respiratory insufficiency, and cardiomyopathy in affected males. Approximately two-thirds of women who have a son with DBMD are heterozygote carriers of the condition. Carriers typically do not manifest muscular symptoms but up to $60 \%{ }^{25}$ are at risk for cardiac abnormalities with one study ${ }^{27}$ finding $10 \%$ of DBMD carriers with development of dilated cardiomyopathy. The American Academy of Pediatrics (AAP) recommends that carriers of DBMD receive a complete cardiac evaluation by a cardiologist between age 25 and 30 that includes echocardiogram and electrocardiogram with re-evaluation every five years. Recent studies ${ }^{33}$ suggest as many as $35.6 \%$ of carriers are not adhering to that five-year recommendation despite having knowledge of their carrier status. Limited research has been conducted into the barriers that carriers of DBMD face in accessing recommended cardiac screening.

Methods: Participants completed a short questionnaire to identify carriers who were and were not following the AAP recommendations. Semi-structured telephone interviews were offered to 11 carriers of DBMD who in the last five years had not seen a

\footnotetext{
${ }^{1}$ Eekhoff, L., Edwards, J., Martin, A., \& Prijoles, E. To be submitted to Journal of Family Practice
} 
cardiologist, had an echocardiogram, had an EKG, or a combination to determine the perceived challenges that carriers face in obtaining appropriate cardiac care.

Results: Most carriers surveyed $(71.7 \%, 43 / 60)$ reported adherence to appropriate cardiac care while $28.3 \%(17 / 60)$ of carriers in our study did not receive appropriate care. From the participants interviewed (11/17), seven major themes emerged as barriers to the receipt of cardiac care. These included a perception amongst carriers that healthcare providers lacked awareness of cardiac risks and associated recommendations. Carriers perceived a decreased risk for cardiac complications due to a perceived healthy lifestyle or lack of family history of cardiac events. Some carriers experienced a lack of information-sharing among family members. Carriers tended to place the healthcare needs of family members above their own. Carriers believed conversations about carrier status should begin at a younger age.

Conclusions: This study called attention to the barriers of obtaining appropriate cardiac care among this population. Increased awareness and advocacy for this unique group is essential with the goal that all members of this population receive the cardiac care that they need.

\subsection{Introduction}

Duchenne and Becker muscular dystrophy (DMD and BMD) are neuromuscular disorders known as dystrophinopathies, caused by X-linked mutations within the dystrophin gene located at chromosome Xp21.1. ${ }^{1}$ Duchenne muscular dystrophy is the most severe of the childhood muscular dystrophies. Symptoms in childhood begin with muscle weakness and wasting that renders affected individuals non-ambulatory

commonly by the age of $12 .{ }^{1,9}$ Dilated cardiomyopathies and arrhythmias typically are 
found in individuals with DMD. In fact, death often occurs in the mid-20s due to cardiac events. $^{14}$

Becker muscular dystrophy is generally a less severe form of muscular dystrophy in which muscle weakness presents later in life. ${ }^{14}$ Affected individuals remain ambulatory longer and death occurs later-into the fourth and fifth decades.

Two-thirds of DBMD are due to pathogenic variants on the $\mathrm{X}$ chromosome inherited from a female carrier. ${ }^{17}$ Carriers typically do not present with symptoms of muscle wasting; however, they are at increased risk for significant cardiac events including hypertrophic involvement, left ventricular dilation, and cardiomyopathy. ${ }^{19,20,24,25,27}$ One group ${ }^{34}$ estimates that approximately $10 \%$ of DBMD carriers will develop overt cardiac failure.

Cardiac disease poses serious health threats to carriers and in some cases requires a transplant or can result in death. ${ }^{26}$ In a study of 129 carriers, Hoogerward et al. ${ }^{25}$ found that approximately $60 \%$ of muscular dystrophy carriers experienced cardiac abnormalities detected by echocardiogram. Of these, $8 \%$ of cardiac abnormalities were dilated cardiomyopathies. In a study ${ }^{24}$ of 36 carriers utilizing cardiac MRI, myocardial damage and fibrosis were detected in $44 \%$ of carriers. Yet another study ${ }^{27}$ of 197 female carriers found that preclinical or clinically-detected myocardial anomalies were found in 84.3\% of cases of DMD and BMD carriers. Furthermore, the significance of preclinical or clinically evident cardiac involvement increased with age with $54.5 \%$ of carriers aged 5 to 16 years old experiencing cardiac involvement and $90.2 \%$ in those older than 16 years. Thus, the possibility of cardiac events in carriers of DBMD is evident, and the cardiac care needs of this population must be consistently addressed. 
The American Academy of Pediatrics (AAP) recommends carriers of DBMD be referred to a cardiac specialist for a complete cardiac evaluation at the time of diagnosis. Subsequent evaluations should occur every five years beginning between the ages of 25 and 30. These evaluations should include EKG, echocardiogram, and consideration for a cardiac MRI. ${ }^{1}$ Evidence suggests that carriers of muscular dystrophy may not be adhering to the AAP recommendations. Bobo et al. ${ }^{33}$ found that of 833 carriers, $35.6 \%$ had never had an echocardiogram despite being aware of their carrier status. A similar study ${ }^{26}$ of 182 women published in 2016 found that only $45.5 \%$ of confirmed carriers had had an echocardiogram in the past five years.

To identify the specific barriers to receiving cardiac care that carriers of DBMD experience, this study aimed to: 1) Determine the specific cardiac care practices that carriers are and are not following 2) Identify perceived challenges and barriers to appropriate cardiac care in this unique population at risk for cardiac disease.

\subsection{Materials and Methods}

\section{Participants}

Women over the age of 18 were eligible to participate in this study if they had a family history indicating their carrier status or if they had completed genetic testing confirming they were a carrier of DBMD. Carrier status was based upon self-reported data. The University of South Carolina Institutional Review Board reviewed the protocol and designated it as exempt from review.

\section{Instrumentation}

A 10-item questionnaire was distributed via a web link (See Appendix A) that was sent in an email to over 500 registrants of DuchenneConnect, an online registry for 
individuals with Duchenne and Becker muscular dystrophy and carrier females in the United States. The study information and questionnaire link were emailed twice. These were first distributed to registered manifesting carriers or confirmed carriers and then to DBMD registrants who reported that their mother was a carrier. The questionnaire assessed: a) Knowledge and confirmation of the participant's own carrier status and b) Personal screening history for cardiac risks. Additionally, the participants could provide contact information if they wished to be contacted for a semi-structured telephone interview. Eligible for the interview were those participants who had not had an EKG, echocardiogram or cardiac MRI in the past five years, or seen a cardiologist in the past five years.

Telephone interviews included questions about participants' initial discovery of their carrier status, current healthcare services received, and challenges they perceived in obtaining appropriate cardiac care (see Appendix B for interview questions). All interviews were recorded using either VoiceRecorder or RecordPad Sound Recorder and were saved on the researcher's private computer under password protection.

\section{Data analysis}

The researcher transcribed all interviews. All transcripts were analyzed for themes using grounded theory data analysis. Interviews were separately reviewed and coded independently by the author and a research assistant. Kappa coefficient was calculated at 0.68. Quantitative data was described by counting response types and through descriptive statistics (percentages and means). All identified themes and representative quotes can be found in Appendix C. 


\subsection{Results}

Sixty individuals registered with DuchenneConnect completed the online questionnaire. Forty-three individuals $(43 / 60,71.7 \%)$ received appropriate cardiac care as evidenced by self-reported receipt of an echocardiogram, EKG, and a visit with a cardiologist within the past five years. Seventeen individuals $(17 / 60,28.3 \%)$ either had not been seen by a cardiologist, had an EKG, or had an echocardiogram in the past five years. Three of these individuals did not provide contact information for a telephone interview. An additional three individuals were unable to be contacted for an interview. Telephone interviews were conducted with eleven individuals. Interviews lasted between 22 and 51 minutes (median 28 minutes).

Many carriers interviewed (9/11) were Caucasian. The majority of carriers worked outside the home (7/11). Education level ranged from completion of high school to doctorate level, master's degree, and law degree. The majority $(9 / 11)$ lived in an urban area. Figure 2.1 indicates states represented by participants interviewed. The two participants from Texas were not related to one another. No participants stated relation to any other participants interviewed. 


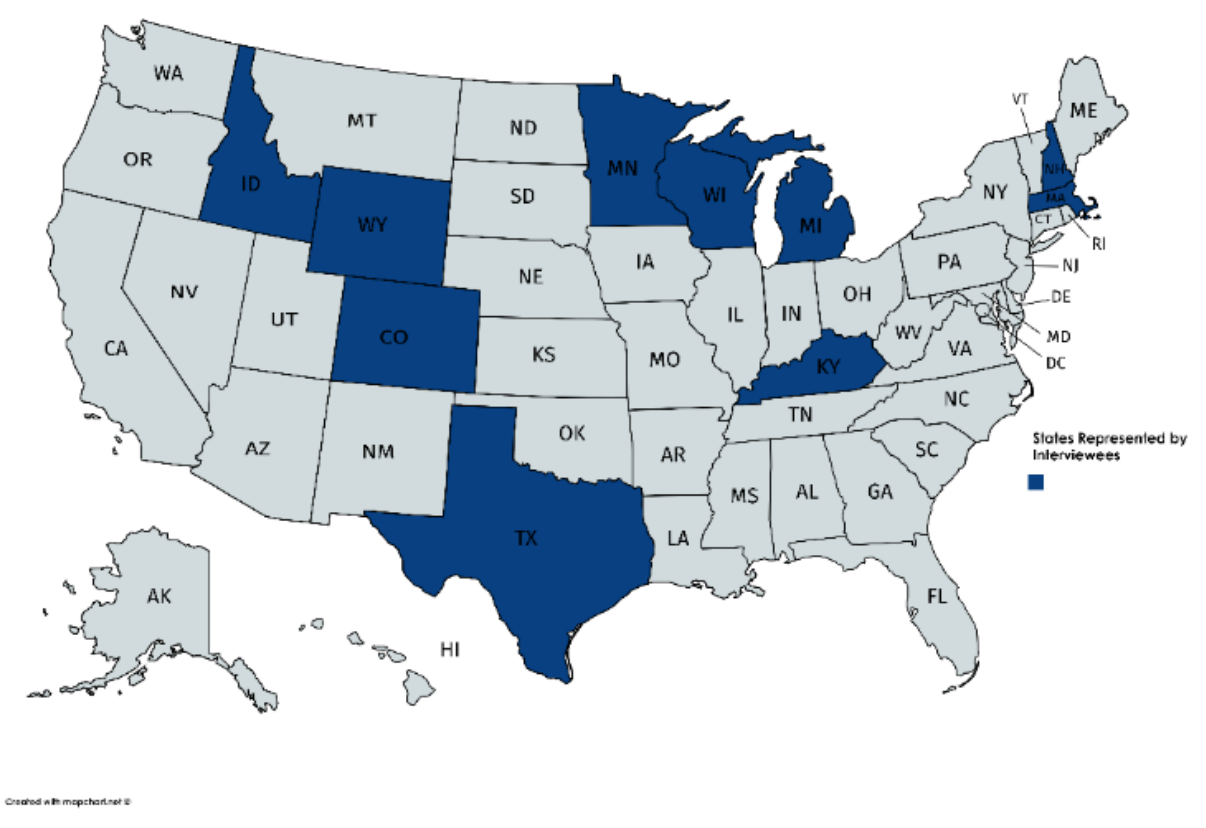

Figure 2.1 States represented by carriers interviewed $(n=11)$. Two carriers interviewed were from Texas.

Most carriers (10/11) had had confirmatory genetic testing with one individual determined to be an obligate carrier based on the pattern of inheritance from her family history.

Much variability existed in the specific cardiac screens that each participant had and had not undertaken. Figure 2.2 represents the specific screenings that the carriers interviewed completed using the recommended five-year interval outlined by the AAP. 


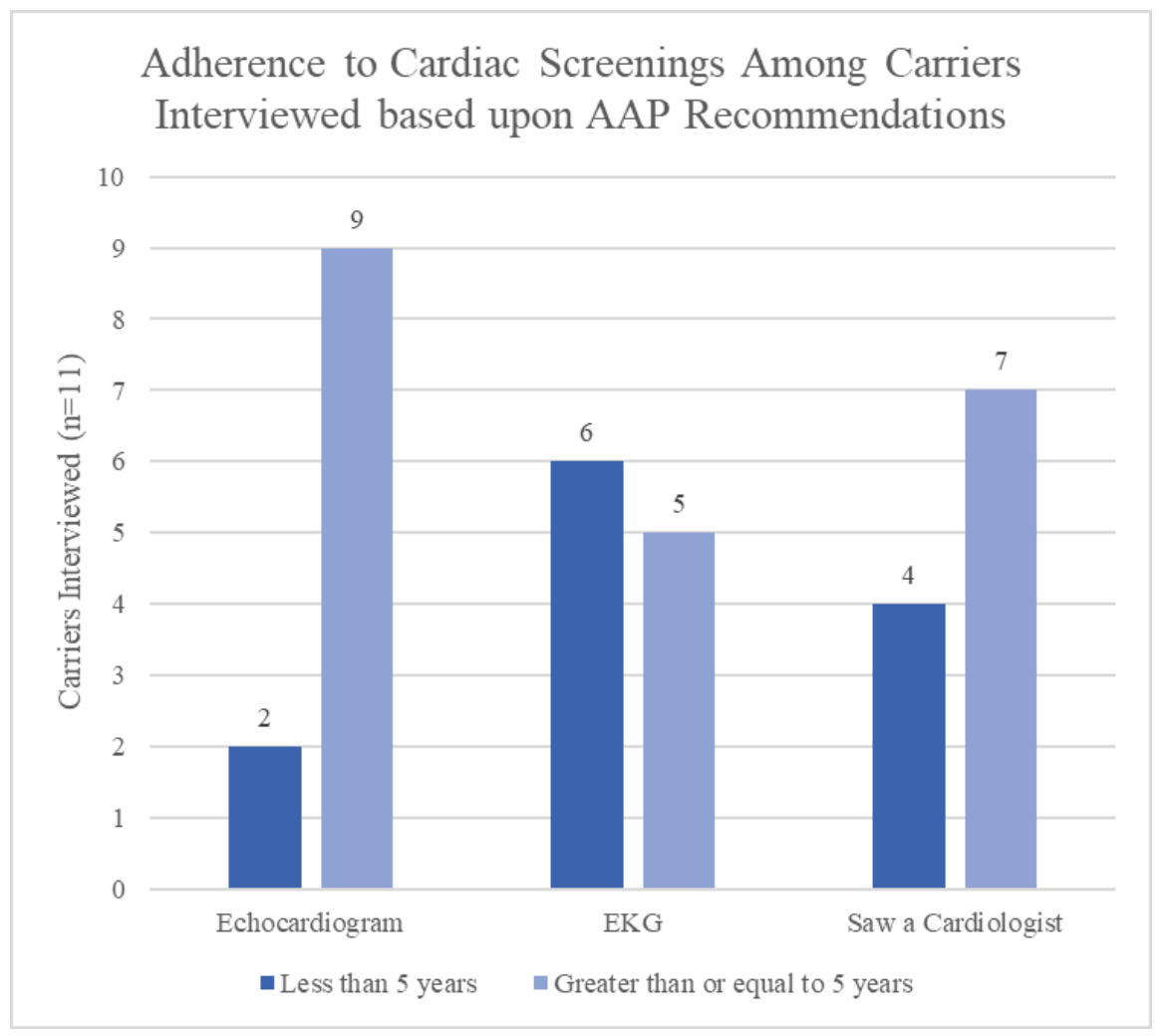

Figure 2.2 Adherence to cardiac screenings among carriers interviewed based upon AAP recommendations $(n=11)$

Participants interviewed ranged in age from 28 to 70 with a mean age of 40 years. Figure 2.3 demonstrates the age at which each participant discovered they were a carrier compared to their age at the time of the interview. An average of 12 years elapsed since participants' discovery of carrier status and the time interviewed representing the amount of time they had not been receiving appropriate cardiac screening. 


\section{Amount of Time Between Participants' Discovery of Carrier Status and Age at Present}

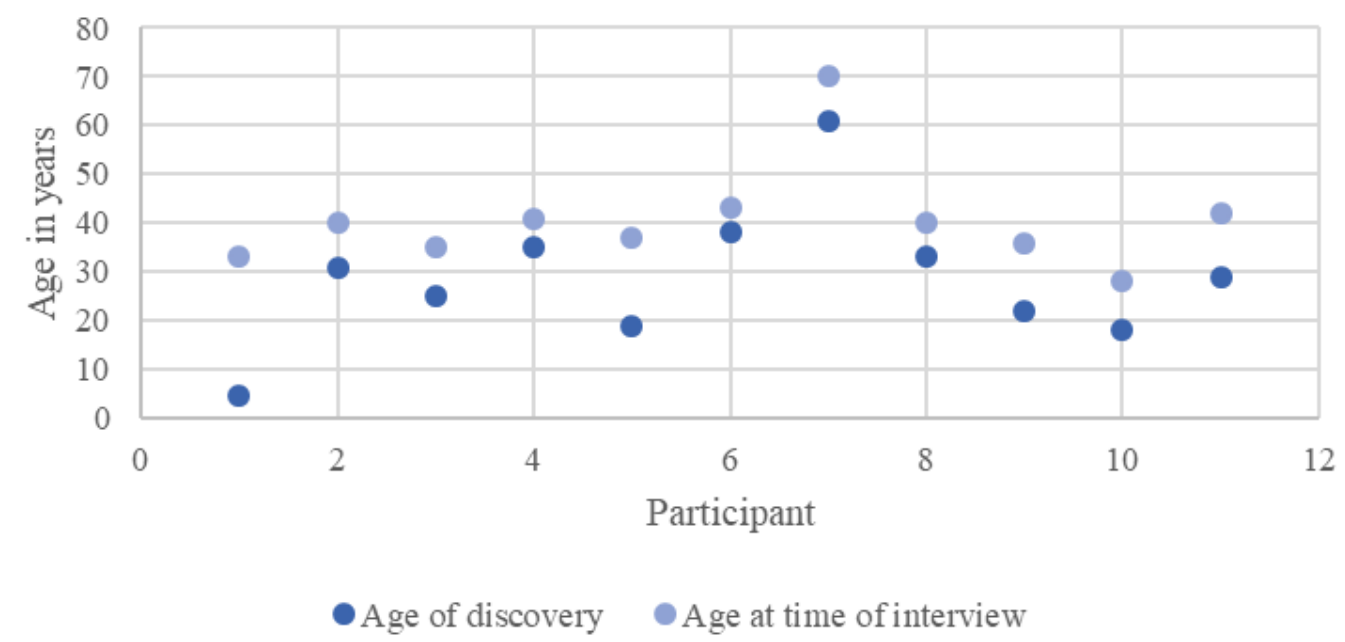

Figure 2.3 Amount of time between participants' discovery of carrier status and age at present $(n=11)$

Many carriers (8/11) had a living son with muscular dystrophy, and most of those individuals (6/8) reported discovering their carrier status while their son was diagnosed with muscular dystrophy. Most carriers (7/10) recalled meeting with a genetic counselor who explained the testing and the results; however, only 5/10 recalled the associated cardiac risks being discussed with them. Notably, even though all carriers interviewed had a primary care physician who was aware of their carrier status, the majority $(8 / 11)$ were unfamiliar with the AAP recommendations for cardiac screening. Additional background information about the participants interviewed can be viewed in Table 2.1. 
Table 2.1 Background information of carriers interviewed $(n=11)$

\begin{tabular}{l|c|c|c|}
\hline \multicolumn{1}{|c}{ Question } & Yes & No & $\begin{array}{c}\text { Not } \\
\text { applicable }\end{array}$ \\
\hline $\begin{array}{l}\text { Do you have a son with muscular } \\
\text { dystrophy? }\end{array}$ & 8 & 3 & \\
$\begin{array}{l}\text { Did you discover your carrier status } \\
\text { upon your son's diagnosis? }\end{array}$ & 6 & 2 & 3 \\
$\begin{array}{l}\text { Do your son's doctors ever discuss } \\
\text { your carrier status? }\end{array}$ & 2 & 5 & 4 \\
$\begin{array}{l}\text { Were you referred for a complete } \\
\text { cardiac evaluation at the time of } \\
\text { diagnosis of carrier status? }\end{array}$ & & & \\
$\begin{array}{l}\text { Are you aware of the AAP } \\
\text { recommendations? }\end{array}$ & 5 & 6 & \\
$\begin{array}{l}\text { Is your PCP aware of your carrier } \\
\text { status? }\end{array}$ & 11 & 0 & \\
\hline
\end{tabular}

Several themes emerged from analysis of the interview transcripts. Each theme is illustrated by verbatim quotes from the interview transcripts.

\section{Theme 1: Carriers experienced a lack of awareness regarding cardiac risks among healthcare providers.}

This most common theme identified was discussed by all carriers interviewed. Carriers reported a lack of understanding among primary healthcare physicians and cardiologists about muscular dystrophy, carriers of muscular dystrophy, and associated cardiac risks. Carriers most often cited among cardiologists that there was an unfamiliarity with the necessity of cardiac screening for carriers. Carriers often felt like they were responsible for educating their healthcare providers about symptoms associated with being a carrier and about the recommended screenings they needed. 
...the PCP was like, "Well why are you here?" type of thing. And

so...basically the PCPs have no clue about, you know, Duchenne or any of

those muscular dystrophy types.

I saw a cardiologist here locally... he had no idea why I was there. It was completely useless. Giant waste of time.

Additionally, some healthcare providers may not be familiar with the AAP recommendations. Some patients (6/11) reported that upon discovery of their carrier status, they were not referred by their healthcare provider for an initial cardiac evaluation as per the AAP recommendations. Many reported receiving misinformation regarding the necessity of frequent examinations.

After I had my first one [cardiac evaluation], they told me, "Your heart is healthy...There's no reason for you to ever come back."

So I took my daughter to see the cardiologist, and the cardiologist dismissed my concerns and said, "You're done. Graduate." And that was that.

\section{Theme 2: Carriers were responsible for educating themselves about risks associated with being a carrier; carriers were their own advocates.}

Despite all carriers reporting that their primary healthcare physician (PCP) was aware of their carrier status (11/11), the majority reported that their PCP did not discuss cardiac risks or remind them to have cardiac screenings. Often this left carriers on their own and forced them to seek out appropriate care independently. 
You're kind of left with it on your own. I had to take initiative with

organizing cardiology appointments. And my doctor won't get on me to remind me to do it because he has no real expertise in that area. When I had my Holter monitor test, I was telling everything to my doctor about my carrier status, and he was on the computer looking it up.

I do have to be the one that asks for these tests. Like [my PCP] ...is not like monitoring it. It's more if I bring it up.

Carriers reported often turning to sources outside healthcare professionals such as the internet or other carriers to receive information about their carrier status. Many acknowledged a frustration with the lack of resources and information and a desire for a more easily accessible and reliable source for information for carriers.

Just like looking it up and just hearing from other people that are carriers as well and not too much detail just kind of word of mouth from what everyone else was saying. So there's not too much on the internet about it, so just from hearing from other...moms that are carriers as well.

Carriers reported the added challenge of working with a healthcare professional who is unaware of a condition, its associated risks, and recommendations for screening. They reported the burden and difficulty of being a self-advocate for their condition.

I think also you kind of need that permission to do [cardiac screenings]. You know like if your doctor's saying you have to go do X, Y, Z you're going to do it. It's a lot harder to go out of your way to say, "You know what, I need to do. I need a screening." 


\section{Theme 3: Carriers were frustrated with the misinformation they had received regarding cardiac risks and wished to be educated about associated risks.}

Carriers reported being unaware of specific risks and recommendations associated with their carrier status. The majority were unfamiliar with the AAP recommendations (8/11). For some, this lack of personal awareness was frustrating. ...it really bothers me. [The AAP recommendations] is something I should have known or been doing all along... maybe it would have answered some questions I had or could explain what was going on with me...or knowing that it was something if I could have caught ahead of time maybe I could have done something about it.

Carriers reported a desire for more information specifically about symptoms to be aware of, the nuances of the different heart screening tests, and what a risk for cardiomyopathy truly means. Despite the desire to be educated about cardiac risks, many carriers discussed the difficulty in obtaining information about carriers of DBMD. They reported obtaining information regarding cardiac risks from a variety of sources including the internet, family members, or other carriers. Oftentimes, this information was not accurate and was presented that carrier status only affects family planning decisions and future pregnancies.

I just also remember like it being communicated to me from [my father] that it doesn't affect that many carriers and it's not something you need to worry about until you're older.

Misinformation included being unaware of the benefit of a cardiac evaluation, a misunderstanding of the mechanism of cardiac risks, and the exact risks associated with 
being a carrier. In some cases, this misinformation resulted in a lack of concern for associated cardiac risks.

I don't really feel like I'm very educated on... what to expect as a carrier, what to be mindful of.

\section{Theme 4: Carriers were unconcerned about cardiac risks due to perceived healthy lifestyles or a lack of a family history of cardiac events.}

Many participants pointed to a lack of family history of cardiac events in other family members who were carriers as evidence of their lack of concern for cardiac risks. Even those who had a history of cardiac events were unconcerned because no healthcare provider had ever associated muscular dystrophy with the history of cardiac events.

I also talked to my mom and she said well our family history-which we know quite well-we don't seem to have that cardiac complication...her mom died of cancer at an advanced age. Her mom who was the sister of the...great-great uncles who would've had Duchenne, she lived deep into her nineties, had no cardiac trouble. Her mom didn't have a cardiac problem either so we figured we were ok to not really bother.

A perceived active and healthy lifestyle including frequent exercise and eating a healthy diet was also cited as a reason for less concern for cardiac complications in carriers.

I ride my bicycle. I go out on long hikes...I you know don't really have any...problems. 


\section{Theme 5: Some carriers experienced a lack of openness and information-sharing with other family members who were also carriers.}

When asked about the amount of information-sharing amongst other carriers in the family, some participants (4/9) reported that they do not discuss their carrier status or cardiac care with other family members, specifically family members who are or are at risk to be carriers of DBMD. Many reported being unsure as to whether those family members received the recommended cardiac screenings. Some reported that the lack of openness was due to feelings of guilt associated with passing on the mutation within the family.

It's kind of a touchy subject, an upsetting subject, because if [my mother] ever found out she was the cause of everything, it would be very upsetting.

Other reasons for a lack of openness among family members included religious beliefs and a lack of apparent symptoms amongst other family members that would otherwise be cause for concern.

There's this strange notion that... amongst their family that... God had punished them somehow by giving them this..it's just like something they just never talk about. I think it's just too painful for my mom's family so I'm a little nervous or shy about bringing it up.

Theme 6: Carriers tended to put the needs of their family members before their own healthcare needs.

The majority of carriers interviewed (8/11) reported having a living son with muscular dystrophy. For some participants (3/11), this meant staying in the home fulltime to provide care for their son. They reported that caregiving for a child with medical 
needs takes a significant amount of time and energy. Often their own healthcare needs took less precedence to the needs of their children.

I'm the last person to think of myself. You know there's so many other things I have to do and the life schedule of living with kids with special needs is hardcore. It is...not easy to find the time to breathe let alone the time to say I should take care of myself...

I'm usually seeing the doctor like when I'm at the end of the rope.

\section{Theme 7: Carriers believed conversations about carrier status and associated risks should begin at an earlier age.}

Participants believed that conversations about carriers and risks should begin at a young age, and information should include more than reproductive-planning and recurrence risks. Some carriers (5/11) recalled at their initial diagnosis that the information delivered was focused on reproductive recurrence risk with little mention of the potential physical symptoms associated with being a carrier.

And it would totally change lives sometimes for the better, sometimes for the worse, but for very different if these girls understood from the very young age...

Carriers acknowledged that often the healthcare needs of those affected with muscular dystrophy became a priority of healthcare professionals and caregivers so that carriers felt more or less forgotten.

Carriers matter and carriers have symptoms...it's not necessarily the muscles, and our life expectancies may indeed be comparable to other 
people, but we have some serious needs that would help our lives so much

to be addressed.

\subsection{Discussion}

This interview-based qualitative study explored the barriers to adherence to the AAP recommendations for cardiac screening amongst carriers of Duchenne and Becker muscular dystrophy. Our screening questionnaire identified that 71.7\% (43/60) carriers received appropriate cardiac screening as outlined by the AAP recommendations. This number is higher than was found in two previous studies of carriers of DBMD; one study ${ }^{33}$ determined that $64.4 \%$ of known carriers had ever had a cardiac evaluation, and a similar study ${ }^{26}$ found that $45.5 \%$ of carriers surveyed had had an echocardiogram in the past five years. The high proportion of carriers in our study that were adhering to the AAP recommendations indicated that the majority of carriers within the DuchenneConnect population are informed of the recommendations and are being appropriately screened by cardiologists. This high percentage may be due to a number of factors. The homogenous group of study participants taken from the DuchenneConnect Registry may have increased access to educational materials through the website and email service provided by the Registry and Parent Project Muscular Dystrophy (PPMD), the advocacy organization that funds the Registry. Both the DuchenneConnect Registry and PPMD may also provide a platform for increased support and accountability from other members to stay up-to-date on cardiac screenings. Additional research is needed to understand the reasons why and how this population is receiving information and is motivated to adhere to the recommendations. 
Despite the finding that the majority of carriers surveyed received appropriate cardiac care, the focus of this study was on the $28.3 \%$ (17/60) who did not adhere to the AAP recommendations. The lack of adherence to the recommendations amongst the minority poses a serious healthcare risk to these carriers. Those risks include an increased likelihood to develop cardiac abnormalities including cardiomyopathy which could result in premature death if left undetected and untreated. Previous research ${ }^{26,33}$ has found that possible reasons for a lack of adherence to the AAP recommendations among DBMD carriers may include factors like lack of personal awareness of cardiac risk, having an uninformed healthcare provider, knowledge of carrier status, and cost.

A number of barriers to accessing cardiac care were identified from the interviews with the eleven carriers in this study. The major theme recognized was a perceived lack of awareness of associated cardiac risks and screening recommendations displayed by cardiologists, primary care physicians, and other healthcare providers. Carriers experienced frustration with healthcare professionals who displayed lack of awareness, resources, and information for carriers. More education efforts may be needed to ensure that healthcare providers are aware of the increased risk for cardiac abnormalities in carriers, of the AAP recommendations, and of appropriate sources for referral.

Carriers were identified as self-advocates and were responsible for self-education regarding their carrier status and associated risks. Frustration with misinformation received and with lack of accessible information available to them was recurrent. A thorough and clear explanation of DBMD carrier status including potential symptoms and risks associated with being a carrier is of utmost importance upon initial diagnosis. Initial 
counseling about the diagnosis should encompass cardiac care for carriers in addition to reproductive risks.

Healthcare providers are in a position to point carriers to appropriate sources of information so that they are informed of cardiac risks and are empowered to seek appropriate care. Many healthcare providers including cardiologists, neurologists, pulmonologists, nutritionists, genetic counselors, and many more specialties are involved in the care of a child with muscular dystrophy. A responsibility of healthcare providers involved on this multidisciplinary team in a muscular dystrophy clinic involves recognizing not only the needs of the child affected with Duchenne or Becker muscular dystrophy, but also his mother who is a potential carrier. A unique opportunity exists for healthcare providers to share appropriate resources and information for mothers who are carriers. This may include educational pamphlets or reputable internet sources. One such online resource is PPMD, (www.parentprojectmd.org) and their DuchenneConnect Registry (www.duchenneconnect.org). The PPMD website provides information on care, research, and advocacy including detailed information for DBMD carriers. DBMD carriers are also encouraged to join the DuchenneConnect Registry.

A lack of family history of cardiac events and a perceived healthy lifestyle may also act as a barrier to receiving cardiac care for some carriers. It is unclear the extent that cardiac abnormalities affect carriers in different families. The lack of family history of cardiac events should not be considered evidence of a decreased risk for an abnormality. Even carriers without a family history of cardiac events among carriers should adhere to the AAP recommendations. The AAP recommends that all carriers require periodic cardiac screening with the rationale that the risk for developing cardiac disease is present 
"irrespective of skeletal muscle disease."1 Inherited cardiomyopathy cannot be prevented; however, carriers should be encouraged to follow healthy lifestyle practices such as frequent exercise and a balanced, heart-healthy diet.

Lack of communication within a family amongst carriers may more easily foster a lack of adherence to AAP recommendations. Previous research has identified that having a female family member with heart disease increased the likelihood of personal receipt of a cardiac test. ${ }^{33}$ Without other family members as a resource for information and accountability, it is important that carriers receive appropriate and accurate information from their healthcare providers regarding necessity and timing of cardiac screenings. Genetic counselors are equipped through their specific training to navigate the difficulty of closed familial relationships and feelings of guilt within a family as well as to address information regarding risks to carriers, the genetic mechanism of disease, and recurrence risks. Recognition of need and identification of referrals to other specialists like genetic counselors may be appropriate in the care of carriers of DBMD.

Carriers may put the healthcare needs of their sons with muscular dystrophy over their own healthcare needs. This is not a unique finding to this population. In fact, previous studies ${ }^{36}$ have shown that caregivers of children with a chronic condition have a significantly lower health-related quality of life which includes areas such as cognitive functioning, sleep, social functioning, daily activities, vitality, and positive and depressive emotions than parents who are not caregivers of a chronically-ill child. Healthcare professionals have the responsibility to emphasize to carriers the importance of adherence to the cardiac care recommendations of the AAP. Beyond that, healthcare 
professionals must recognize the burden of caregiving experienced by an individual and should be prepared to offer support.

Carriers desired that conversations about their carrier status begin at an earlier age and include more than information regarding reproductive recurrence risk. Genetic testing of a minor may act as a barrier to determination of carrier status until a potential carrier reaches the age of 18 ; however, many healthcare providers and families are now open to carrier testing of children under the age of 18 . Communication within the family unit about carriers and their associated risks should be encouraged by healthcare providers.

This study offered insight into the challenges that carriers of DBMD faced in obtaining recommended cardiac care. As indicated by the carriers interviewed in this study, the most significant barrier to obtaining cardiac care was a perceived lack of education and awareness experienced among healthcare providers. The goal of this study was to call attention to the needs of this population and to provide education for those medical professionals who serve them. We hope that this study will be valuable to the healthcare community and will prompt personal evaluation, and a potential adjustment of practice, of each individual provider's interaction with members of this unique population. Increased awareness and advocacy efforts are necessary until the entire group, that is carriers of Duchenne and Becker muscular dystrophy, is able to receive appropriate cardiac care.

\section{Limitations}

Study participants were registrants of DuchenneConnect and thus this study surveyed a small proportion of carriers of DBMD who are actively seeking information 
through this organization. Sixty carriers completed the survey of the over five hundred registrants to whom the survey was sent. The majority of our participants were Caucasian and highly educated. Findings from this study were specific to participants interviewed and cannot be generalized to the larger population of carriers of muscular dystrophy.

\section{Future research}

Future research may include an exploration of the different sources of information provided to carriers and their efficacy in prompting cardiac screening. Additionally, future research should target a larger, more heterogenous group of carriers to determine more accurately the specific barriers to obtaining appropriate cardiac care experienced. Further, more research is warranted into the significant majority of carriers identified in this study that are receiving appropriate cardiac care. This may include more in-depth research into the specific information individuals have received regarding carrier status, associated risks, and patient resources.

\section{Conclusions}

A significant number of DBMD carriers received appropriate cardiac care based upon the AAP recommendations. A perceived lack of education and awareness among healthcare providers was a barrier most often reported by carriers who were not receiving appropriate cardiac care. Increased educational and awareness efforts are needed among healthcare providers and carriers about DBMD to promote increased adherence to cardiac screening among all DBMD carriers. 


\section{CHAPTER 3:}

\section{CONCLUSIONS}

Carriers of Duchenne and Becker muscular dystrophy are at increased risk for cardiac complications including cardiomyopathy. Previous research has found that some carriers may not be adhering to the AAP recommendations that state that every five years, carriers should be seen by a cardiologist and receive an EKG and echocardiogram.

This study found that $71.7 \%$ of carriers surveyed received appropriate cardiac care. Of the $28.3 \%$ who did not receive recommended care, several themes were identified that represented barriers to obtaining appropriate care. The most common theme discussed was a perceived lack of awareness among healthcare providers and available resources for carriers.

Healthcare providers including primary care physicians, cardiologists, genetic counselors, and all those involved in the care of carriers of DBMD have the responsibility to be well-informed regarding the needs of this population. Carriers as well as healthcare providers can work together to promote increased awareness and advocacy so as to ensure the needs of this group are met. 


\section{REFERENCE LIST}

1. American Academy of Pediatrics Section on Cardiology and Cardiac Surgery. (2005). Cardiovascular health supervision for individuals affected by Duchenne or Becker muscular dystrophy. Pediatrics, 116(6), 1569-1573.

https://doi.org/10.1542/peds.2005-2448

2. Kamdar, F., \& Garry, D. J. (2016). Dystrophin-Deficient Cardiomyopathy. Journal of the American College of Cardiology, 67(21), 2533-2546. https://doi.org/10.1016/j.jacc.2016.02.081

3. Sansović, I., Barišić, I., \& Dumić, K. (2013). Improved detection of deletions and duplications in the DMD gene using the multiplex ligation-dependent probe amplification (MLPA) method. Biochemical Genetics, 51(3-4), 189-201. https://doi.org/10.1007/s10528-012-9554-9

4. Juan-Mateu, J., Gonzalez-Quereda, L., Rodriguez, M. J., Baena, M., Verdura, E., Nascimento, A., ... Gallano, P. (2015). DMD Mutations in 576 Dystrophinopathy Families: A Step Forward in Genotype-Phenotype Correlations. PloS One, 10(8), e0135189. https://doi.org/10.1371/journal.pone.0135189

5. Mendell, J. R., Shilling, C., Leslie, N. D., Flanigan, K. M., al-Dahhak, R., GastierFoster, J., ... Weiss, R. B. (2012). Evidence-based path to newborn screening for Duchenne muscular dystrophy. Annals of Neurology, 71(3), 304-313. https://doi.org/10.1002/ana.23528 
6. Flanigan, K. M., Dunn, D. M., von Niederhausern, A., Soltanzadeh, P., Gappmaier, E., Howard, M. T., ... Weiss, R. B. (2009). Mutational spectrum of DMD mutations in dystrophinopathy patients: application of modern diagnostic techniques to a large cohort. Human Mutation, 30(12), 1657-1666. https://doi.org/10.1002/humu.21114

7. Hoogerwaard, E. M., Bakker, E., Ippel, P. F., Oosterwijk, J. C., Majoor-Krakauer, D. F., Leschot, N. J., ... de Visser, M. (1999). Signs and symptoms of Duchenne muscular dystrophy and Becker muscular dystrophy among carriers in The Netherlands: a cohort study. Lancet (London, England), 353(9170), 2116-2119.

8. Noritz, G. H., Murphy, N. A., \& Panel, N. S. E. (2013). Motor Delays: Early Identification and Evaluation. Pediatrics, 131(6), e2016-e2027. https://doi.org/10.1542/peds.2013-1056

9. Connolly, A. M., Florence, J. M., Cradock, M. M., Malkus, E. C., Schierbecker, J. R., Siener, C. A., ... MDA DMD Clinical Research Network. (2013). Motor and cognitive assessment of infants and young boys with Duchenne Muscular Dystrophy: results from the Muscular Dystrophy Association DMD Clinical Research Network. Neuromuscular Disorders: NMD, 23(7), 529-539. https://doi.org/10.1016/j.nmd.2013.04.005

10. Hendriksen, J. G. M., \& Vles, J. S. H. (2008). Neuropsychiatric disorders in males with duchenne muscular dystrophy: frequency rate of attention-deficit hyperactivity disorder (ADHD), autism spectrum disorder, and obsessive--compulsive disorder. Journal of Child Neurology, 23(5), 477-481. https://doi.org/10.1177/0883073807309775 
11. Mewton, N., Liu, C. Y., Croisille, P., Bluemke, D., \& Lima, J. A. C. (2011). Assessment of myocardial fibrosis with cardiovascular magnetic resonance. Journal of the American College of Cardiology, 57(8), 891-903.

12. Tandon, A., Villa, C. R., Hor, K. N., Jefferies, J. L., Gao, Z., Towbin, J. A., ... Taylor, M. D. (2015). Myocardial fibrosis burden predicts left ventricular ejection fraction and is associated with age and steroid treatment duration in duchenne muscular dystrophy. Journal of the American Heart Association, 4(4). https://doi.org/10.1161/JAHA.114.001338

13. Yiu, E. M., \& Kornberg, A. J. (2015). Duchenne muscular dystrophy. Journal of Paediatrics and Child Health, 51(8), 759-764. https://doi.org/10.1111/jpc.12868

14. Flanigan, K. M. (2014). Duchenne and Becker muscular dystrophies. Neurologic Clinics, 32(3), 671-688, viii. https://doi.org/10.1016/j.ncl.2014.05.002

15. Biggar, W. D., Harris, V. A., Eliasoph, L., \& Alman, B. (2006). Long-term benefits of deflazacort treatment for boys with Duchenne muscular dystrophy in their second decade. Neuromuscular Disorders: NMD, 16(4), 249-255. https://doi.org/10.1016/j.nmd.2006.01.010

16. Robinson-Hamm, J. N., \& Gersbach, C. A. (2016). Gene therapies that restore dystrophin expression for the treatment of Duchenne muscular dystrophy. Human Genetics, 135(9), 1029-1040. https://doi.org/10.1007/s00439-016-1725-z

17. Davie, A. M., \& Emery, A. E. (1978). Estimation of proportion of new mutants among cases of Duchenne muscular dystrophy. Journal of Medical Genetics, 15(5), $339-345$. 
18. Lee, T., Takeshima, Y., Kusunoki, N., Awano, H., Yagi, M., Matsuo, M., \& Iijima, K. (2014). Differences in carrier frequency between mothers of Duchenne and Becker muscular dystrophy patients. Journal of Human Genetics, 59(1), 46-50. https://doi.org/10.1038/jhg.2013.119

19. Soltanzadeh, P., Friez, M. J., Dunn, D., von Niederhausern, A., Gurvich, O. L., Swoboda, K. J., ... Flanigan, K. M. (2010). Clinical and genetic characterization of manifesting carriers of DMD mutations. Neuromuscular Disorders: NMD, 20(8), 499-504. https://doi.org/10.1016/j.nmd.2010.05.010

20. Moser, H., \& Emery, A. E. (1974). The manifesting carrier in Duchenne muscular dystrophy. Clinical Genetics, 5(4), 271-284.

21. Darras, B. T., Miller, D. T., \& Urion, D. K. (1993). Dystrophinopathies. In M. P. Adam, H. H. Ardinger, R. A. Pagon, S. E. Wallace, L. J. Bean, H. C. Mefford, ... N. Ledbetter (Eds.), GeneReviews(®). Seattle (WA): University of Washington, Seattle. Retrieved from http://www.ncbi.nlm.nih.gov/books/NBK1119/

22. Viggiano, E., Ergoli, M., Picillo, E., \& Politano, L. (2016). Determining the role of skewed X-chromosome inactivation in developing muscle symptoms in carriers of Duchenne muscular dystrophy. Human Genetics, 135(7), 685-698. https://doi.org/10.1007/s00439-016-1666-6

23. Vo, A. H., \& McNally, E. M. (2015). Modifier genes and their effect on Duchenne muscular dystrophy. Current Opinion in Neurology, 28(5), 528-534. https://doi.org/10.1097/WCO.0000000000000240

24. Florian, A., Rösch, S., Bietenbeck, M., Engelen, M., Stypmann, J., Waltenberger, J., ... Yilmaz, A. (2016). Cardiac involvement in female Duchenne and Becker muscular 
dystrophy carriers in comparison to their first-degree male relatives: a comparative cardiovascular magnetic resonance study. European Heart Journal Cardiovascular Imaging, 17(3), 326-333. https://doi.org/10.1093/ehjci/jev161

25. Hoogerwaard, E. M., van der Wouw, P. A., Wilde, A. A., Bakker, E., Ippel, P. F., Oosterwijk, J. C., ... de Visser, M. (1999). Cardiac involvement in carriers of Duchenne and Becker muscular dystrophy. Neuromuscular Disorders: NMD, 9(5), $347-351$.

26. Bogue, L., Peay, H., Martin, A., Lucas, A., \& Ramchandren, S. (2016). Knowledge of carrier status and barriers to testing among mothers of sons with Duchenne or Becker muscular dystrophy. Neuromuscular Disorders: NMD, 26(12), 860-864. https://doi.org/10.1016/j.nmd.2016.09.008

27. Politano, L., Nigro, V., Nigro, G., Petretta, V. R., Passamano, L., Papparella, S., ... Comi, L. I. (1996). Development of cardiomyopathy in female carriers of Duchenne and Becker muscular dystrophies. JAMA, 275(17), 1335-1338.

28. Mccaffrey, T., Guglieri, M., Murphy, A. P., Bushby, K., Johnson, A., \& Bourke, J. P. (2017a). Cardiac involvement in female carriers of duchenne or becker muscular dystrophy. Muscle \& Nerve, 55(6), 810-818. https://doi.org/10.1002/mus.25445

29. Mavrogeni, S., Markousis-Mavrogenis, G., Papavasiliou, A., \& Kolovou, G. (2015). Cardiac involvement in Duchenne and Becker muscular dystrophy. World Journal of Cardiology, 7(7), 410-414. https://doi.org/10.4330/wjc.v7.i7.410

30. Schelhorn, J., Schoenecker, A., Neudorf, U., Schemuth, H., Nensa, F., Nassenstein, K., ... Schlosser, T. (2015). Cardiac pathologies in female carriers of Duchenne 
muscular dystrophy assessed by cardiovascular magnetic resonance imaging. European Radiology, 25(10), 3066-3072. https://doi.org/10.1007/s00330-015-3694-3

31. Hunt, S. A., Abraham, W. T., Chin, M. H., Feldman, A. M., Francis, G. S., Ganiats, T. G., ... Heart Rhythm Society. (2005). ACC/AHA 2005 Guideline Update for the Diagnosis and Management of Chronic Heart Failure in the Adult: a report of the American College of Cardiology/American Heart Association Task Force on Practice Guidelines (Writing Committee to Update the 2001 Guidelines for the Evaluation and Management of Heart Failure): developed in collaboration with the American College of Chest Physicians and the International Society for Heart and Lung Transplantation: endorsed by the Heart Rhythm Society. Circulation, 112(12), e154-235. https://doi.org/10.1161/CIRCULATIONAHA.105.167586

32. Politano, L., \& Nigro, G. (2012). Treatment of dystrophinopathic cardiomyopathy: review of the literature and personal results. Acta Myologica: Myopathies and Cardiomyopathies: Official Journal of the Mediterranean Society of Myology, 31(1), $24-30$.

33. Bobo, J. K., Kenneson, A., Kolor, K., \& Brown, M. A. (2009). Adherence to american academy of pediatrics recommendations for cardiac care among female carriers of duchenne and becker muscular dystrophy. Pediatrics, 123(3), e471-475. https://doi.org/10.1542/peds.2008-2643

34. Bushby, K., Muntoni, F., \& Bourke, J. P. (2003). 107th ENMC international workshop: the management of cardiac involvement in muscular dystrophy and myotonic dystrophy. 7th-9th June 2002, Naarden, the Netherlands. Neuromuscular Disorders: NMD, 13(2), 166-172. 
35. Peay, H. L., Meiser, B., Kinnett, K., Furlong, P., Porter, K., \& Tibben, A. (2016). Mothers' psychological adaptation to Duchenne/Becker muscular dystrophy. European Journal of Human Genetics: EJHG, 24(5), 633-637. https://doi.org/10.1038/ejhg.2015.189

36. Hatzmann J, Heymans HSA, Ferrer-i-Carbonell A, van Praag BMS, Grootenhuis MA. Hidden consequences of success in pediatrics: parental health-related quality of life-results from the Care Project. Pediatrics. 2008;122(5):e1030-1038.

doi:10.1542/peds.2008-0582 


\section{APPENDIX A:}

\section{WEB-BASED QUESTIONNAIRE}

This is a research project being conducted by Lauren Eekhoff at the University of South Carolina in Columbia, SC. The purpose of this research project is to identify the challenges that women who are known to be carriers of Duchenne or Becker Muscular Dystrophy (DBMD) experience in obtaining cardiac surveillance. You are invited to take this questionnaire if you have a living or deceased son with Duchenne or Becker Muscular Dystrophy and you have been found to be a carrier.

This study contains two parts: 1) a 10-minute questionnaire intended to determine if you are a carrier of DBMD 2) a 30-minute phone interview in which you will be asked questions regarding the specific challenges that you experience in obtaining cardiac care. This is the main focus and vital piece of the study, and if you would be willing to participate in an interview, there will be a designated location at the end of the questionnaire where you can provide your contact information. Your responses will be kept confidential. The results of this study will be used for scholarly purposes only.

Your participation in this research study is voluntary. You may choose not to participate. If you decide to participate in this research study, you may withdraw at any time. If you decide not to participate in this study or if you withdraw from participating at any time, you will not be penalized.

Please complete this questionnaire only once. If you do not reach the "Thank you for completing the survey" page at the end, your responses may not be included in the final analysis.

*1. Clicking on the "agree" button below indicates that:

- you have read the above information

- you voluntarily agree to participate

- you are at least 18 years of age

If you do not wish to participate in the research study, please decline participation by clicking on the "disagree" button.

2. Check the box next to the one statement that applies to you:

I have a living son (or sons) with Duchenne or Becker Muscular Dystrophy 
I no longer have any living sons with Duchenne or Becker Muscular Dystrophy

I have never had any sons with Duchenne or Becker Muscular Dystrophy

3. Check the box next to the statement that best describes you:

I know my carrier status, and I am a Duchenne or Becker Muscular Dystrophy carrier

C carrier

I know my carrier status, and I am not a Duchenne or Becker Muscular Dystrophy

I do not know my carrier status

C I am not sure what this question is asking

4. How did you confirm your carrier status? Select all that apply.

$\Gamma$ I had genetic testing

$\Gamma \quad$ I had a blood test but I am not sure if it was genetic testing

$\ulcorner$ I am an obligate carrier (meaning that my carrier status is certain based on the pattern

of affected boys in my family)

$\Gamma$ A physician told me

$\Gamma$ A genetic counselor told me

Г I am not sure

$\ulcorner$ Other method (please specify)

5. Please tell us the most recent time (month and year) you...

... saw a cardiologist

...had an ECG (test that checks the heart rhythm)

...had an echocardiogram or cardiac MRI (tests that look at the heart)

6. How many sons with Duchenne or Becker do you/did you have? Include those who are deceased.
Zero
One
Two or more

7. Mark the statement which is most true for you and your extended family. In choices B and C, consider "my son" to mean your first affected son if you have had more than one son with Duchenne or Becker.

a. My son (or sons) is the only person in the family with Duchenne or Becker.

b. My son was the only person in the family with Duchenne or Becker at the time he was diagnosed, but since then, at least one other family member (not another son of my own) has been diagnosed with Duchenne or Becker Muscular Dystrophy 
C

c. My son was not the first person in the family to be diagnosed with Duchenne or Becker; there was a family history of the condition prior to my pregnancy with my son.

d. I am not sure / none of these seem true for my family

8. This study includes an interview conducted via phone call that will last approximately 30-40 minutes. Your participation is greatly appreciated and your responses invaluable to this study. Would you be willing to participate in the interview portion of this study?

○ Yes

o No

9. Please provide your preferred contact information so that we may contact you to set up the interview for this study. Your contact information will not be linked to your responses. Participation is voluntary.

Name:

Email:

Cell Phone:

Home Phone:

Questionnaire used with permission from Bogue et al., 2016. 


\section{APPENDIX B: \\ INTERVIEW QUESTIONS}

\section{Carrier Status Discovery (Educational Barrier)}

1. Tell me about the time when you discovered you were a carrier of muscular dystrophy.

a. When? (How many years ago was this?)

b. How old were you?

c. Was this the same time that your son was diagnosed?

d. Who informed you of your carrier status?

e. What information did you receive during that diagnosis? How was it explained to you?

f. Do you feel that the information you received was sufficient at that time or were you left with questions?

g. Do you know who to contact if you do have questions?

h. Were you referred for a complete cardiac evaluation at that time of diagnosis?

Self-care Current Practices (Perceived Risk Barrier)

1. Are you aware of any health risks associated with being a carrier of MD?

2. How concerned are you with the health risks associated with being a carrier?

3. Are you aware of the American Academy of Pediatrics' recommendations for carriers of MD? (cardiac eval every 5 years)

a. How important is it to you to follow the AAP recommendations for cardiac evaluation?

b. Have you ever been seen by a cardiologist?

c. When was the last time you had an ECG and/or an echocardiogram? A cardiac MRI?

Barriers/Challenges (Relationship with healthcare provider, lack of support, access to healthcare, emotional burden, denial? Barriers)

1. What are your reasons for having (not having) an ECG and/or echocardiogram?

2. Tell me about your relationship with your primary healthcare provider.

a. Is he/she aware of your carrier status?

b. How frequently do you discuss your carrier status/associated health risks?

3. Do you have any other females in your family that have had genetic testing and are carriers of muscular dystrophy?

a. What is your relationship like with them?

b. Do you feel comfortable discussing matters related to your own health with them 
4. Tell me about your access to cardiac care/a cardiologist.

a. Is it easy for you to get to your appointments?

b. How long does it take you to get to a cardiologist?

c. What is your relationship like with your cardiologist?

d. Do you feel comfortable asking him/her any questions you may have?

5. Tell me about being a mother of a child with a condition like muscular dystrophy.

a. Do you attend all his healthcare appointments with him?

b. Do any of the specialists ever discuss your own cardiac health issues?

c. Many mothers have to balance their family's health care need with taking care of their own health care needs. Oftentimes, mom's healthcare needs get put on the back-burner. How is this for you?

6. Tell me about the routine healthcare screenings you partake in annually.

a. When was your last mammogram, colonoscopy, physical, etc.?

7. The ultimate goal of this study is to raise awareness of healthcare professionals about the needs of carriers of DBMD. What do you want your cardiologist, genetic counselor, etc. to know about your healthcare needs? Is there any way you can think that would help us serve you better?

Demographics

8. What is your age?

9. What is your ethnicity?

10. What is your race?

11. What is your current occupation?

12. What is the highest level of education you have completed?

13. Where do you live? (city; rural/urban?) 


\section{APPENDIX C: MAJOR THEMES AND REPRESENTATIVE QUOTES}

\begin{tabular}{|c|c|c|}
\hline $\begin{array}{c}\text { Carriers experience a lack of } \\
\text { awareness regarding cardiac risks } \\
\text { among healthcare providers in } \\
\text { general. }\end{array}$ & $\begin{array}{c}\text { Carriers are responsible for } \\
\text { educating themselves about risks } \\
\text { associated with being a carrier and } \\
\text { are their own advocates. }\end{array}$ & $\begin{array}{l}\text { Carriers are frustrated with the } \\
\text { misinformation regarding cardiac } \\
\text { risks. }\end{array}$ \\
\hline $\begin{array}{l}\text { Anyway they're not familiar around } \\
\text { here with this disease where I live. }\end{array}$ & $\begin{array}{l}\text { You know I didn't know about that } \\
\text { [increased cardiac risks], and actually } \\
\text { she [my mother] didn't know about } \\
\text { that until I did research. I got really } \\
\text { curious about it, and I wanted to know, } \\
\text { you know, all about it and about being } \\
\text { a carrier and all that. }\end{array}$ & $\begin{array}{l}\text { When they say I'm a carrier and there's } \\
\text { a risk for cardiomyopathy like what does } \\
\text { that really mean? Like is it because of the } \\
\text { amount of deletion genes that I'm } \\
\text { missing? Like yeah I think it's just } \\
\text { understanding that more and being more } \\
\text { aware of that. }\end{array}$ \\
\hline $\begin{array}{l}\text { I guess they've felt like you know an } \\
\text { EKG and then a Holter monitor worn } \\
\text { for twenty-four hours was was enough } \\
\text { to give them you know the information } \\
\text { they needed. }\end{array}$ & $\begin{array}{l}\text { It's more for myself initiating it } \\
\text { [cardiologist appointments]. }\end{array}$ & $\begin{array}{l}\text { I'd like to be educated on uhm perhaps } \\
\text { specifically what tests should be done } \\
\text { every five years. That was like big news } \\
\text { to me that you told me that. Uhm and I } \\
\text { would say uhm like what symptoms to } \\
\text { look out for in general. Uhm and in } \\
\text { terms of cardiac uhm and also be to } \\
\text { being aware of uhm the appropriate } \\
\text { resources that I can do to get more } \\
\text { information or more support. }\end{array}$ \\
\hline $\begin{array}{l}\text { I don't know how to deal with } \\
\text { physicians cuz like I said you've got } \\
\text { some physicians that test you and } \\
\text { they're way proactive and look things } \\
\text { up and then you've got other } \\
\text { physicians who deal with it all the } \\
\text { time... And you kinda have to tell them } \\
\text { what the recommendation is. }\end{array}$ & $\begin{array}{l}\text { When I make an appointment again I'm } \\
\text { going to make sure that I have my } \\
\text { son's doctor, Shanti's doctor, write } \\
\text { something down or I don't know find } \\
\text { something electronic to my cardiologist } \\
\text { to let them know why I'm coming in } \\
\text { for testing. Or I guess it's like people } \\
\text { aren't familiar with it. }\end{array}$ & $\begin{array}{l}\text { How it was framed it was like, "This } \\
\text { isn't an issue until you decide to have } \\
\text { children," which I think is like generally } \\
\text { true uhm but I kinda wish with that there } \\
\text { had been a little bit more of } \\
\text { conversation. }\end{array}$ \\
\hline $\begin{array}{l}\text { Each cardiologist is like, "I have no } \\
\text { idea why you're here." And I explain } \\
\text { to them because of muscular } \\
\text { dystrophy if I'm a carrier that means I } \\
\text { may have cardiomyopathy I think it is } \\
\text { and then something with my kidneys. } \\
\text { Yep and both of them had no idea } \\
\text { what I was talking about. }\end{array}$ & $\begin{array}{l}\text { Where I found out about uhm what } \\
\text { carrier care I needed was from the } \\
\text { MDA website. }\end{array}$ & $\begin{array}{l}\text { Do cardiologists actually see people like } \\
\text { me for that reason? }\end{array}$ \\
\hline
\end{tabular}


Carriers are unconcerned about cardiac risks due to perceived healthy lifestyles or a lack of a family history of cardiac events.

Some carriers experience a lack of openness with other family members who are also carriers.
Carriers tend to put the needs of their family members before their own healthcare needs.
Carriers believe conversations about carrier status and associated risks should begin at an earlier age.
I'm not too worried about it. Uhm I don't have any like. With my mom being a carrier, she's never even had. Actually after she found out she's a carrier, they did a workup on her heart. She's never had any problems so I'm really not worried about it.
And I think if my mom found out she was a carrier it probably would be devastating for her. That's why in the very beginning I never said you should get tested too.
So how much time do we spend caregiving? 24/7 yeah. And that's that's really both my husband and me spending essentially all of our time caregiving for these adorable kids who absolutely deserve it.
If my mother had knew [about my carrier status] and she had explained it to me when I was growing up and everything that might have saved me a lot of always being a mystery every time I went to the doctor about you know what was going on with my body and all that.
She [my mother] didn't have any real cardiac you know. And so my grandmother who would've been a carrier didn't have any you know cardiac issues.... I felt like because of the family history that I'm not really at risk for it.
I think it was hard for her [my mother] to talk about so she never said anything.
I was trying to work a job. I was trying to take care of him. I never had time for myself. I never had time to take myself to the doctor. I never had time to uhm to really care for myself.
They will not allow us to test for her [my daughter] because she's not of age of consent until she turns 18 and I was a little bit upset about that but you know I was like well I'm not saying that she would but say if she would get pregnant at 13 , I would like to know so that I can educate my daughter.
It's just like in our family like I mean yeah there's been heart issues but like nothing's been directly linked to muscular dystrophy. So like it's never really concerned me.

I try to eat you know well and everything. I exercise at least 4 to 5 times a week. At least I'm exercising and things like that. So you know just try to keep myself healthy as possible.
I feel like my dad is able to talk more Things like that where something about it. I will say like there is a part of is like you know I have an injury me that feels uhm like hesitant or kinda or something. I'm kinda like, shy away from bringing it up with him "Eh whatever. I'll wait until it uhm I think because there's this gets worse or whatever." Cuz I dynamic of both my parents were in mainly want him and my healthcare and I think they adopted daughter like their whatever their this, "Unless you're seriously sick appointments and their stuff first you're totally fine."
She [mom] thinks all this is her fault. She doesn't understand the genetics and I explained to her the science and the genetics, "This is not your

fault."...they don't understand that and neither do her sisters 